Marquette University

e-Publications@Marquette

$1-2020$

\title{
Adaptive Functioning in High-Risk Preschoolers: Caregiver Practices Beyond Parental Warmth
}

Kristen Yule

Christina Murphy

John Grych

Follow this and additional works at: https://epublications.marquette.edu/psych_fac

Part of the Psychology Commons 
Marquette University

e-Publications@Marquette

\title{
Psychology Faculty Research and Publications/College of Arts and Sciences
}

This paper is NOT THE PUBLISHED VERSION.

Access the published version via the link in the citation below.

Journal of Child and Family Studies, Vol. 29, No. 1 (January 2020): 115-127. DOI. This article is (C) Springer and permission has been granted for this version to appear in e-Publications@Marquette. Springer does not grant permission for this article to be further copied/distributed or hosted elsewhere without express permission from Springer.

\section{Adaptive Functioning in High-Risk Preschoolers: Caregiver Practices Beyond Parental Warmth}

\author{
Yule, Kristen
}

Department of Psychology, Marquette University, Milwaukee, WI

Murphy, Christina

Department of Psychology, Marquette University, Milwaukee, WI

Grych, John

Department of Psychology, Marquette University, Milwaukee, WI

\footnotetext{
Abstract

Objectives: Prior research on caregiving behaviors associated with resilience in children exposed to adversity has focused primarily on broad constructs, such as parental warmth and supportiveness, as protective factors. In an effort to provide more precise analysis of caregiver behaviors related to adaptive functioning in high-risk preschoolers, the present study used a multi-method design to examine the unique and joint relations of specific emotion socialization behaviors and parental warmth with adaptive functioning in preschool-aged children.
} 
Methods: Participants were 124 children aged 3-6 years from Head Start programs and their primary caregiver. Caregivers and teachers reported on preschoolers' functioning across multiple domains (emotion regulation, social competence, school readiness, and low levels of emotional/behavioral problems), and caregivers' emotion coaching, validating, and invalidating behaviors were measured with self-report and observation.

Results: The emotion socialization behaviors together accounted for significant variance on a global index of adaptive functioning after accounting for exposure to adversity, with emotion coaching serving as a unique predictor. Further, parental warmth moderated the association between particular behaviors (caregiver-reported emotion coaching and observed emotional invalidation) and adaptive functioning.

Conclusions: These results suggest that engaging in emotion socialization behaviors in the context of a warm and supportive relationship can promote positive developmental outcomes in high-risk preschoolers.

\section{Keywords}

Resilience; Adaptive functioning; Adversity; Preschoolers; Emotion socialization; Parental warmth

An estimated nine million children under the age of five in the United States are exposed to significant adversity (e.g., poverty, violence in the family and community, death of a family member; Data Resource Center for Child and Adolescent Health [14]), putting them at increased risk for a range of maladaptive outcomes, including emotional, social, academic, and behavioral difficulties (e.g., Kim and Cicchetti [41]). Stressful experiences in early childhood can disrupt developing regulatory systems, including self-control of attention, emotions, and behavior (Thompson [73]), which in turn impact children's ability to accomplish age-related developmental tasks or milestones, such as forming friendships and working independently (Masten [53]). However, a substantial number of children who experience high levels of stress and adversity demonstrate successful adaptation, or resilience (Luthar et al. [51]; Masten et al. [54]; Masten and Tellegen [57]; Rutter [66]). Understanding protective factors related to adaptive functioning in preschool-aged children is particularly important because the onset of formal schooling presents a set of new cognitive, social, and behavioral demands, and children who struggle to meet these demands have difficulty catching up to their peers later in childhood and adolescence (Buhs et al. [9]). Identifying protective and promotive factors associated with healthy development at this age therefore has important implications for later adjustment. However, the majority of resilience research has focused on middle childhood and adolescence (Graham-Bermann et al. [29]; Klika and Herrenkohl [42]), and consequently less is known about predictors of resilience in preschoolers.

Resilience is defined by the presence of adaptive functioning despite experiencing significant stress and adversity, but many studies have operationalized resilience simply as low levels of clinical symptomatology (Yule et al. [75]). Low levels of pathology are important indicators of healthy functioning, but they are not synonymous with the presence of health. Luthar ([50]) highlights the importance of assessing positive outcomes across multiple domains, noting that narrow definitions can 
underestimate children's adaptive functioning (also see Klika and Herrenkohl [42]). One important conceptualization of resilience emphasizes the mastery of age-specific developmental milestones after experiencing adversity (Masten et al. [55]). Key milestones during the preschool period include increasing independent regulation of emotions, effective interaction with peers, and readiness for formal schooling (Centers for Disease Control and Prevention [10]; Masten and Coatsworth [56]).

Preschoolers exhibit growing awareness and understanding of their emotions, which in turn fosters increasing ability to manage heightened levels of pleasant and unpleasant feelings, inhibit undesirable impulses and behavior, and to self-soothe and recover from emotional arousal and distress (Posner and Rothbart [63]). Adaptive emotion regulation in turn is related to children's social and academic competence and ability to cope with stress (Gross and Muñoz [30]; McCabe and Altamura [58]). Preschoolers also develop greater capacity to interact effectively with peers and form friendships, which predicts mental health, well-being, and academic competence during preschool and grade school years (Denham et al. [17]; Ladd [44]). Finally, preschoolers demonstrate growth in school readiness skills, including following directions, sitting still, paying attention, and completing tasks (Blair [6]). These capacities create a foundation for children to develop academic competencies, such as emergent literacy, numeracy, and oral language skills and contribute to school adjustment and achievement (Lonigan et al. [47]). Children exposed to higher levels of stress and adversity are less likely to master these developmental tasks and thus tend to experience more academic, social, and mental health difficulties in the elementary school years (Obradović et al. [61]).

Parent-child relationships consistently have been identified as protective factors for children exposed to violence and adversity (for a review, see Yule et al. [75]) and consequently have been a primary emphasis for prevention programs developed for young children (Borden et al. [ 7]; Lieberman et al. [46]). Most studies documenting the protective function of parenting have assessed broad constructs such as "warmth" or "supportiveness" (Bell et al. [ 5]; Quiroga et al. [64]), and while they provide important information about factors that may foster adaptive functioning, they are less helpful for identifying specific behaviors that could be taught in prevention and intervention programs.

Research on emotion socialization provides a promising direction for studying how caregivers can promote healthy development in young children who have experienced significant adversity. Emotion socialization practices help children learn to recognize, understand, and manage their emotions (Denham et al. [19]; Eisenberg et al. [22]), and are related to better psychological adjustment from preschool through adolescence (Katz et al. [37]; Lunkenheimer et al. [49]; Zeman et al. [77]). Most of this work has involved general community samples, and leading emotion socialization theorists have called for more attention to the potential for emotion socialization practices to promote healthy development in children exposed to adversity, who face increased threats to their developing regulatory capacities (see Katz et al. [39]; Lemerise [45]; Zeman et al. [76]). Initial studies of at-risk samples are encouraging. For example, emotion coaching (i.e., attending to, discussing, and providing guidance to children on how to regulate their emotions; Gottman et al. [28]) has been shown to buffer the effects of interparental violence on behavioral adjustment in preschoolers (Katz and WindeckerNelson [40]) and social competence in middle childhood (Katz et al. [38]), as well as to predict better emotion regulation in preschool- and elementary school-aged children exposed to varying levels of family adversity (Ellis et al. [24]; Katz et al. [39]). Similarly, mothers' emotion validation (i.e., awareness 
and nonjudgmental acceptance) and coaching predicted greater emotional competence in 9-13 year old's living in neighborhoods with high levels of violence (Cunningham et al. [13]). Caregivers' emotional socialization behaviors also were found to predict indicators of executive functioning in a sample of maltreated preschoolers (Fay-Stammbach et al. [26]). In contrast, invalidating responses to children's expression of emotion, which can involve dismissing, criticizing, mocking, lecturing, or minimizing children's emotions, may cause emotional avoidance or internalization over time, which has been associated with maladaptive functioning in 7-12 year old children (Shaffer et al. [68]). These findings suggest that emotion socialization practices are related to the socioemotional development of children who have experienced high levels of stress and adversity, but few studies have examined these practices in relation to adaptive functioning in at-risk preschoolers.

Furthermore, the quality of parental warmth (i.e., a general tendency to be positive, caring, and affectionate during parent-child interactions) provides an important context that may enhance or undermine the impact of parents' responses to their children's emotions. For example, when a caregiver who generally is caring and nurturing asks questions about a child's emotional experiences, it is likely to promote the child's capacity to attend to, understand, and express painful feelings. In contrast, the same questions posed by a caregiver who usually is unsupportive or critical may seem like an interrogation and elicit defensiveness or shame instead. Examining emotion socialization behaviors in isolation also makes it unclear if these behaviors are unique predictors of adaptive functioning or if they are a reflection of the quality of the caregiver-child relationship. Therefore, we tested the following research questions to integrate work on emotion socialization with research on broader dimensions of parenting identified as protective for at-risk youth. First, are specific emotion socialization behaviors related to indicators of adaptive functioning in a sample of at-risk preschoolers? Second, are these parenting behaviors uniquely related to adaptive functioning after accounting for (a) children's exposure to adversity and (b) parental warmth? This second question tested whether any associations between emotion socialization and adaptive functioning remained significant after including two variables that often correlate with child adjustment. Third, does parental warmth moderate the association between emotion socialization behaviors and child adjustment such that the combination of warmth and emotion socialization behaviors better predicts adaptive functioning than either construct alone? This question addressed the possibility that helping children to manage their emotions has a more powerful impact when children have a strong and supportive relationship with their caregivers.

\section{Method}

\section{Participants}

Participants were 124 child-caregiver dyads from Head Start preschools in a midsized Midwestern city. Children from grades K3 through K5 (51\% male) ranged from 3 to 6 years of age $(M=3.96)$ and were predominantly Black or African American (93\%), with smaller numbers as multiracial (6\%) and Latino or Hispanic (1\%), as identified by caregivers. Primary caregivers were between the ages of 19 and 69 years $(M=32)$, were predominately female (86\%), and identified primarily as Black or African American $(91 \%)$, with smaller numbers identifying as multiracial (5\%), White (2\%), and Latino or Hispanic (2\%). Most caregivers had earned a high school or higher educational degree (94\%). A majority of caregiver participants were the child's mother (77\%), with smaller numbers identifying as the child's father 
(13\%), grandmother (6\%), grandfather (2\%), and aunt (2\%). Approximately $40 \%$ of children had two or more primary caregivers, including fathers (33\%), grandmothers (12\%), and grandfathers (5\%). To be eligible for Head Start, families had to have incomes below federal poverty guidelines. In exchange for participation, caregivers were provided a twenty-dollar gift card and a certificate of completion.

\section{Procedure}

Families were recruited through informational flyers. After informed consent was obtained, dyads engaged in a discussion about the child's emotions that was videorecorded and used to assess parenting behaviors. Caregivers then privately completed questionnaires regarding their children's exposure to adversity and adjustment, as well as their own warmth and use of emotion coaching behaviors. Teachers also were asked to complete two measures regarding the child's functioning. The university's institutional review board approved all procedures.

\section{Measures}

\section{The parent-child emotion interaction task}

(PCEIT; Shipman et al. [70]) is an observational procedure that assesses caregivers' responses to children's emotions. Discussing their child's emotional experiences provides an important opportunity for caregivers to help children recognize, accept, and manage their affect, and so children were asked to "talk with your (mom/dad/grandparent) about a time that you felt (i.e., happy, angry, sad)."

Caregivers were instructed to respond to their child as they normally would, and to provide guidance if the child struggled to come up with a time they experienced each feeling. Dyads talked about each of the three emotions, which were presented in random order, for 1 to $5 \mathrm{~min}(M=2.5 \mathrm{~min})$.

The PCEIT was coded for caregivers' validating and invalidating responses using the PCEIT Global Coding Scales (Shipman et al. [70]). These scales measure caregiver validation and invalidation separately on two seven-point scales for each emotion, with higher scores indicating higher levels of validation or invalidation, respectively. The codes take into account both the frequency and quality of verbal and non-verbal behaviors. Validating behaviors include emotion focused listening skills (e.g., repeat/rephrase the child's words), empathic understanding of the child's emotional experiences (e.g., 'That would make me feel sad too.'), and helping children understand and cope with their feelings (e.g., 'What helped you feel better?'). Invalidating behaviors include those that minimize or dismiss children's unpleasant emotions (e.g., 'That's not worth being sad about.'), express disbelief or doubt about an emotional experience (e.g., 'Really!? You felt mad!?'), or criticize or blame children for their feelings (e.g., 'I wouldn't have yelled if you had listened to me.'). Past research supports the interrater reliability and construct validity of this coding system (Schneider and Shipman [67]). Separate scores were obtained for validation and invalidation by summing scores across the three emotions, with possible scores ranging from 0 to 18 for validation and invalidation scales. The first author coded all interactions, and a research assistant double coded $20 \%$ of the interactions. An interrater reliability analysis using intra-class correlation coefficients (ICC) indicated high levels of agreement (validation, ICC single score range $=0.97-0.98$; invalidation, ICC single score range $=0.97-1.00$ ) .

Emotion coaching was measured via self-report with the 5-item subscale of the Emotion Related Parenting Styles (ERPS; Paterson et al. [31]), with items rated on a 5-point scale ( 1 = Always false, 5 = Always true). Sample items include, "It is important to help my child find out what caused their 
anger" and "When my child is sad, I try to help him or her figure out why the feeling is there." Responses were summed to create a total score representing emotion coaching behavior. The emotion coaching subscale has shown strong convergent validity with other measures of parental socialization of coping and emotional expressiveness (Paterson et al. [31]) and demonstrated good internal consistency in the current sample $(\alpha=0.76)$.

Parental warmth was assessed using the 20-item warmth/affection subscale from the Parental Acceptance-Rejection Questionnaire (PARQ; Rohner et al. [65]), with items rated on a 4-point scale (1 = Almost Never True, 4 = Almost Always True). Sample items include, "I let my child know I love him/her" and "I make my child feel what he/she does is important." Responses were summed to create a total score, with higher scores indicating greater warmth and affection. The PARQ demonstrated strong internal consistency $(\alpha=0.90)$.

Adaptive functioning was operationalized by four developmental tasks that are salient during the preschool years (Masten and Coatsworth [56]). To obtain independent perspectives on children's functioning in the home and school contexts, caregivers and teachers completed measures of emotion regulation, social competence, school readiness, and behavioral adjustment. We combined these measures to create a multifaceted composite of adaptive functioning following the "summative" approach (Luthar and Cushing [52], p. 144) used in prior studies of resilience (Banyard and Williams [4]; Cicchetti and Rogosch [11]). Specifically, percentiles were calculated separately for caregiver and teacher reports of the four domains of adaptive functioning: children earned a score of 0 if they were below the $33^{\text {rd }}$ percentile (low competence), 1 if they were between the 33rd and 67th percentile (average competence), and 2 if they were above the 67th percentile (high competence). This resulted in eight variables (four variables per rater) that were summed together to create a composite of adaptive functioning, which could range from 0 to 16, with higher numbers indicating better levels of adjustment.

Emotion Regulation. Children's emotion regulation was assessed using caregivers' responses on the Emotion Regulation Checklist (ERC; Shields and Cicchetti [69]) and the emotion regulation subscale on the Preschool Behavioral and Emotional Rating Scale (PreBERS; Epstein and Synhorst [25]). Due to a moderate correlation between measures $(r=0.54, p=0.001)$, caregiver responses on the ERC and PreBERS emotion regulation subscale were converted to $z$-scores and combined to represent caregivers' report of children's emotion regulation; this combined caregiver-report score was used to calculate percentiles included in the adaptive functioning composite score. The $E R C$ is a 24item self-report measure, with items rated on a 4-point scale ( $1=$ Rarely/never to $4=$ Almost always) and included items such as, "can recover quickly from disappointment or distress," and "exhibits mood swings." Responses were reverse scored when appropriate and summed to produce a total score representing effective emotion regulation abilities. The ERC demonstrated strong internal consistency with an alpha of 0.85 . The 13 -item PreBERS emotion regulation subscale was completed by caregivers and teachers. Responses were rated on a 4-point scale ( $0=$ Not at all, $3=$ Very much $)$ and included items such as, "controls anger toward others" and "reacts to disappointments calmly." Responses were summed to represent effective emotion regulation abilities. The emotion regulation subscale demonstrated strong internal consistency (caregiver $\alpha=0.89$ and teacher $\alpha=0.94$ ). 
School Readiness. Children's school readiness skills were assessed using the 13-item PreBERS' school readiness subscale (Epstein and Synhorst [25]), with items rated on a 4-point scale (0=Not at all, 3 = Very much). Sample items include "understands complex sentences" and "pays attention to tasks." Responses were summed to create a total score representing school readiness, with higher scores indicating greater academic abilities. The school readiness subscale showed strong internal consistency (caregiver $\alpha=0.91$ and teacher $\alpha=0.93$ ).

Social Competence. Children's social skills were assessed using the 9-item social confidence subscale of the PreBERS (Epstein and Synhorst [25]), with responses rated on a 4-point scale (0 = Not at all, 3 = Very much). Sample items include "asks others to play" and "takes turns in play situations." Responses were summed to create a total score of social competence, with higher scores indicating greater social skills. The social competence subscale has shown good convergent validity with other measures of social functioning (Nordness et al. [60]) and demonstrated strong internal consistency in the current sample (caregiver $\alpha=0.87$ and teacher $\alpha=0.85$ ).

Behavioral Adjustment. Children's behavioral adjustment were assessed using caregiver reports on the Anxious/Depressed, Withdrawn, and Aggressive Behavior subscales of the Child Behavior Checklist for Ages 11/2-5 (CBCL/1.5-5; Achenbach and Rescorla [1]) and teacher reports on the Teacher Report Form for Ages 11/2-5 (TRF/1.5-5; Achenbach and Rescorla [1]). Respondents indicated how true a statement is for a child "now or within the past 2 months" on a 3-point scale $(0=$ Not true, $2=$ Very true or often true). Sample items for each of the three scales include, respectively, "feelings are easily hurt," "seems unresponsive to affection," and "hits others." Responses were reverse coded and summed to create a total score of behavioral adjustment, with higher scores indicating greater competence (i.e., fewer emotional/behavioral problems). The combined subscales demonstrated strong internal consistency (CBCL $\alpha=0.92$ and TRF $\alpha=0.96)$.

All of the children participating in the study experienced socioeconomic disadvantage, as reflected by their eligibility for Head Start (i.e., income below the federal poverty line), but we included additional measures to better describe the range of adversities they were exposed to in and outside the home. We assessed several forms of adversity shown to be commonly experienced by preschool-aged children (Data Resource Center for Child and Adolescent Health [14]), including witnessing and directly experiencing multiple forms of violence, serious accidents, and loss of family members through death, divorce, and incarceration. Since we were interested in capturing the cumulative risk experienced by children rather than the frequency of specific kinds of adversity, we followed a method used in prior studies (e.g., Appleyard et al. [ 3]; Herrenkohl and Herrenkohl [34]) to create a composite variable that combined scores across the following caregiver-reported measures. The risk composite was created by summing 46 dichotomous items ( $0=$ No or $1=Y e s)$ across the three measures to represent the total forms of adversity experienced by children. Composite scores could range from 0 to 46 , with higher numbers indicating greater exposure to adverse life experiences.

Exposure to violence was assessed using the 25-item Juvenile Victimization Questionnaire (JVQ; Finkelhor et al. [27]). Subscales included conventional crime, peer and sibling victimization, past sexual victimization, and witnessing indirect victimization. Caregivers indicated either $0=$ No or $1=$ Yes. Sample items include, "Was your child in a place where he/she could see or hear people being shot, bombs going off, or street riots?" and "Was anyone close to your child 
murdered, like a friend, neighbor, or someone in your family?" The JVQ demonstrated strong internal consistency $(\alpha=0.83)$.

Exposure to traumatic life events was assessed using the 13-item Childhood Trust Events Survey (CTES; Pearl [62]), with caregivers indicating either $0=$ No or $1=Y e s$. Sample items include, "Was your child ever in a really bad accident, such as a serious car accident," and "Has your child ever had a family member who was put in jail or prison or taken away by the police?" Because these life events would not be expected to covary, internal consistency is not reported for the CTES.

Interparental aggression was measured using four 4-item subscales from Conflict Tactic Scale Short Form (CTS2S; Straus and Douglas [72]), including psychological aggression, assault, injury, and sexual coercion, that assess mild to severe victimization and perpetration of partner abuse within the past year. Sample items include "threw or smashed or hit or kicked something," and "insulted or swore at each other." Caregiver responses ranged from $0=$ Never to $7=$ More than 20 times. Since respondents do not indicate whether children were present or not during each instance, each subscale of the CTS2S was reduced to two dichotomous items (i.e., $0=$ No or $1=Y e s$ ) to assess the presence of victimization and perpetration for each of the four types of interparental violence that children may have been exposed to. This resulted in eight items that were summed to create a total score of interparental aggression that could range from 0 to 8 . The internal consistency was good $(\alpha=0.82)$.

\section{Results}

Descriptive statistics for each of the parenting variables, adversity measures, and adaptive functioning variables can be found in Table 1 . According to caregivers, $90 \%$ of preschool participants were exposed to at least one type of adversity during their lifetime $(M=5.55, S D=4.53)$ in addition to socioeconomic disadvantage, and nearly half experienced more than four types of adversity. On average, caregivers reported at least one instance of interparental aggression $(M=1.83, S D=1.93)$, exposure to violence $(M=2.47, S D=3.09)$, and experience of a traumatic life event $(M=1.35, S D=1.37)$. The most common types of adversities reported included psychological interparental aggression (60\%), being physically hit by another child (48\%), having a family member incarcerated (32\%), and having a close family member die unexpectedly (31\%). 
Table 1. Descriptive statistics and correlations among parenting, adaptive functioning, and adversity measures $(N=122)$

\begin{tabular}{|c|c|c|c|c|c|c|c|c|c|c|c|c|c|}
\hline Variables & 1 & 2 & 3 & 4 & 5 & 6 & 7 & 8 & 9 & 10 & 11 & 12 & 13 \\
\hline 1. Parental warmth (caregiver-reported) & - & & & & & & & & & & & & \\
\hline 2. Parental validation (observed) & 0.14 & - & & & & & & & & & & & \\
\hline 3. Parental invalidation (observed) & 0.01 & 0.07 & - & & & & & & & & & & \\
\hline 4. Emotion coaching (caregiver-reported) & $0.47 * * *$ & 0.06 & 0.03 & - & & & & & & & & & \\
\hline 5. Adaptive functioning composite & $0.43^{* * *}$ & 0.11 & 0.03 & $0.36 * * *$ & - & & & & & & & & \\
\hline 6. Emotion regulation & $0.41 * * *$ & 0.15 & 0.04 & $0.30 * *$ & $0.84 * * *$ & - & & & & & & & \\
\hline 7. School readiness & $0.36 * * *$ & 0.05 & 0.10 & $0.36 * * *$ & $0.80 * * *$ & $0.48 * * *$ & - & & & & & & \\
\hline 8. Social competence & $0.31 * *$ & 0.08 & -0.12 & $0.32 * * *$ & $0.77^{* * *}$ & $0.45^{* * *}$ & $0.71 * * *$ & - & & & & & \\
\hline 9. Behavioral adjustment & $0.31 * *$ & 0.07 & 0.06 & 0.15 & $0.76 * * *$ & $0.70 * * *$ & $0.37 * * *$ & $0.30 * * *$ & - & & & & \\
\hline 10. Adversity composite & $-0.19 *$ & -0.02 & -0.05 & 0.03 & -0.07 & -0.12 & -0.02 & 0.10 & $-0.18^{*}$ & - & & & \\
\hline 11. Exposure to violence & -0.1 & -0.03 & -0.04 & 0.10 & -0.07 & -0.12 & 0.01 & 0.09 & -0.20 & $0.87 * * *$ & - & & \\
\hline 12. Traumatic life events & 0.02 & 0.03 & 0.04 & 0.14 & 0.01 & -0.06 & 0.12 & 0.08 & -0.12 & $0.63 * * *$ & $0.42 * * *$ & - & \\
\hline 13. Interparental aggression & $-0.32 * * *$ & -0.06 & -0.09 & $-0.23^{*}$ & -0.07 & -0.06 & -0.16 & 0.03 & -0.05 & $0.52 * * *$ & 0.15 & 0.09 & - \\
\hline $\mathrm{M}$ & 5.84 & 7.79 & 6.64 & 22.11 & 8.44 & 0.69 & 0.72 & 0.78 & 0.69 & 5.55 & 2.47 & 1.35 & 1.83 \\
\hline SD & 0.89 & 2.15 & 1.35 & 3.52 & 4.06 & 0.71 & 0.72 & 0.68 & 0.72 & 4.53 & 3.09 & 1.37 & 1.94 \\
\hline Range & $1-7$ & $1-14$ & $3-12$ & $5-25$ & $0-16$ & $0-2$ & $0-2$ & $0-2$ & $0-2$ & $0-23$ & $0-15$ & $0-5$ & $0-8$ \\
\hline$\alpha$ & 0.90 & 0.73 & 0.53 & 0.76 & 0.77 & 0.90 & 0.91 & 0.83 & 0.95 & 0.80 & 0.83 & & 0.82 \\
\hline
\end{tabular}

${ }^{*} p<0.05 ;{ }^{* *} p<0.001 ;{ }^{* * *} p<0.001$ 
Despite the high average rate of adversity exposure, a majority of preschool participants demonstrated healthy functioning in at least one domain of adjustment. We compared participants' scores on the measures of functioning to normative data reported for each measure and found that most of the preschoolers' scores were at or above the mean values on the scale. According to caregivers, $94 \%$ of preschool participants demonstrated above average levels of competence in at least one domain of adjustment, while $49 \%$ of preschoolers demonstrated above average competence in at least three of the four domains. According to teachers, $88 \%$ of preschool participants demonstrated above average levels of competence in at least one domain of adjustment, while $34 \%$ demonstrated above average competence in at least three of the four domains. Children were most likely to demonstrate adaptive functioning in the domain of school readiness as reported by caregivers (95\%) and teachers (84\%). Children who demonstrated healthy adjustment in one domain were more likely to exhibit it in others (see Table 1): positive correlations were found between child emotion regulation, social competence, and school readiness ( $r$ s ranging from 0.45 to 0.85 ), which were all associated with fewer emotional/behavioral problems ( $r$ s ranging from 0.30 to 0.75 ).

On average, caregivers reported fairly high levels of parental warmth $(M=5.84, S D=0.89)$ and emotion coaching $(M=22.11, S D=3.52)$, and were observed to engage in moderate to high levels of both validating $(M=7.79, S D=2.15)$ and invalidating $(M=6.64, S D=1.35)$ behaviors. All caregivers in the study were observed to engage in emotion focused listening $(M=28.37, S D=12.50)$ behaviors to validate children's emotions, whereas fewer caregivers helped their child understand and cope with their emotions $(22 \% ; M=0.41, S D=0.92)$ or verbalized empathic understanding $(18 \% ; M=0.22, S D=$ 0.52 ). The most common invalidating behaviors observed included caregivers lecturing or teaching the child a lesson ( $46 \% ; M=1.08, S D=1.65)$, telling children how they should or should not feel $(46 \% ; M=$ $0.24, S D=0.58)$, and expressing doubt or disbelief $(46 \% ; M=0.79, S D=1.13)$ towards children's emotional experiences, whereas minimizing $(9 \% ; M=0.12, S D=0.42)$ and criticizing $(4 \% ; M=$ $0.08, S D=0.43$ ) children's emotions was less frequently observed.

Scores on the $P A R Q$ were non-normally distributed in the sample, with moderate skewness of -1.5. As a result, caregiver-reported warmth scores were transformed using a square root transformation (Howell [35]) and these transformed values were used for all subsequent analyses. Two participants had scores on the $P A R Q$ that were more than $3 S D$ from the mean, and thus were dropped from the following analyses. Male and female caregivers did not demonstrate significantly different levels of warmth, validation, or invalidation. Caregivers who reported higher parental warmth also reported higher levels of emotion coaching, but self-reports of parental warmth and emotion coaching were not significantly associated with either observed validating or invalidating behaviors (see Table 1).

\section{Relations between Emotion Socialization Behaviors and Adaptive Functioning in} Preschoolers

Correlational analyses were conducted among the adversity, parenting, and adaptive functioning variables (see Table 1). Caregiver-reported parental warmth and emotion coaching were positively correlated with children's emotion regulation, social competence, school readiness, and overall adaptive functioning, while only parental warmth was related to fewer emotional/behavioral problems. Observed validating and invalidating behaviors were not significantly associated with the adaptive functioning composite or individual indicators. The global index of adversity was related to 
lower parental warmth and more behavior problems but not overall adaptive functioning or observed or caregiver-reported emotion socialization behaviors.

A hierarchical multiple regression analysis was conducted using the adaptive functioning composite as the outcome variable to examine whether any of the emotion socialization behaviors uniquely predicted adaptive functioning after accounting for exposure to adversity and caregiver-reported parental warmth. We entered the adversity composite in the first step of the regression equation along with children's age and sex, which often are correlated with child adjustment; together, these covariates explained $9 \%$ of the variance in adaptive functioning. Self-reported parental warmth was entered in the second step and explained an additional $24 \%$ of the variance. Observed validating and invalidating, and self-reported emotion coaching behaviors were entered in the third step and together added significantly to the prediction of adaptive functioning, explaining an additional $26 \%$ of the variance. Caregiver-reported emotion coaching was the only emotion socialization variable that uniquely predicted adaptive functioning in the final step of the equation (see Table 2).

Table 2. Hierarchical multiple regression analysis predicting global index of adaptive functioning $(N=$ 122)

\begin{tabular}{|l|l|l|l|}
\hline & Model 1 & Model 2 & Model 3 \\
\hline Variable & $\boldsymbol{\beta}$ & $\boldsymbol{\beta}$ & $\boldsymbol{\beta}$ \\
\hline Child sex & $0.22^{*}$ & $0.27^{* *}$ & $0.28^{* *}$ \\
\hline Child age & $0.21^{*}$ & 0.16 & 0.16 \\
\hline Adversity composite & -0.11 & 0.07 & -0.03 \\
\hline Parental warmth (caregiver-reported) & & $0.43^{* * *}$ & $0.31^{* * *}$ \\
\hline Parental validation (observed) & & & 0.05 \\
\hline Parental invalidation (observed) & & & -0.01 \\
\hline Emotion coaching (caregiver-reported) & & & $0.22^{*}$ \\
\hline $\mathrm{R}^{2}$ & 0.09 & 0.24 & 0.26 \\
\hline F for change in $\mathrm{R}^{2}$ & $4.01^{* *}$ & $10.26^{* * *}$ & $6.94^{* * *}$ \\
\hline
\end{tabular}

$* p<0.05 ; * * p<0.01 ; * * * p<0.001$

Parental Warmth Moderating the Relationship between Emotion Socialization Behaviors and Adapt...

Following Aiken and West's ([ 2]) guidelines, moderation analyses were conducted to examine whether parental warmth moderated the relationship the emotion socialization behaviors (validation, invalidation, emotion coaching) and the adaptive functioning composite. To preserve power, separate hierarchical regression analyses were conducted for the three emotional socialization behaviors. After accounting for child sex, age, and adversity exposure, caregiver-reported parental warmth significantly moderated the association between two of the parenting behaviors (caregiver-reported emotion coaching, observed invalidation) and the adaptive functioning composite (see Table 3), indicating that the association between the parenting behaviors and adaptive functioning depended on the level of parental warmth. Interactions were probed using the Johnson-Neyman region of significance (ROS) technique and simple slopes with conventional guidelines (+/- 1 SD from the mean of the moderator). The ROS was used to identify the range of the moderator variable where the simple slopes differed significantly from zero, which provides a more precise assessment of the moderating effect than 
examining slopes at arbitrarily chosen points (Hayes and Matthes [32]). Simple slopes analyses were conducted to help illustrate the nature of the interactions. 
Table 3. Testing the moderation of warmth and specific parenting practices in predicting adaptive functioning $(N=122)$

\begin{tabular}{|c|c|c|c|c|c|c|c|c|c|c|c|c|}
\hline & $\begin{array}{l}\text { Caregiver- } \\
\text { Reported } \\
\text { Emotion } \\
\text { Coaching }\end{array}$ & & & & $\begin{array}{l}\text { Observed } \\
\text { Parental } \\
\text { Validation }\end{array}$ & & & & $\begin{array}{l}\text { Observed Parental } \\
\text { Invalidation }\end{array}$ & & & \\
\hline & Model 1 & Model 2 & Model 3 & Model 4 & Model 1 & $\begin{array}{l}\text { Model } \\
2 \\
\end{array}$ & $\begin{array}{l}\text { Model } \\
3\end{array}$ & \begin{tabular}{|l|} 
Model \\
4
\end{tabular} & Model 1 & $\begin{array}{l}\text { Model } \\
2 \\
\end{array}$ & $\begin{array}{l}\text { Model } \\
3\end{array}$ & $\begin{array}{l}\text { Model } \\
4\end{array}$ \\
\hline Variable & $\beta$ & $\beta$ & $\beta$ & $\beta$ & $\beta$ & $\beta$ & $\beta$ & $\beta$ & $\beta$ & $\beta$ & $\beta$ & $\beta$ \\
\hline Child sex & $0.21 *$ & $0.26 * *$ & $0.28 * *$ & $0.25^{* *}$ & $0.20 *$ & $0.19 *$ & $0.26^{* *}$ & $0.27 * *$ & $0.20 *$ & $0.20 *$ & $0.27^{* *}$ & $0.27 * *$ \\
\hline Child age & $0.19 *$ & 0.15 & 0.14 & 0.11 & 0.15 & 0.17 & 0.15 & 0.13 & 0.15 & 0.16 & 0.15 & $0.17^{*}$ \\
\hline Adversity composite & -0.11 & -0.12 & -0.03 & -0.01 & -0.07 & -0.07 & 0.02 & 0.02 & -0.07 & -0.08 & 0.02 & 0.01 \\
\hline Parenting behavior & & $0.38 * * *$ & $0.23 *$ & $0.28 * *$ & & 0.12 & 0.06 & 0.05 & & -0.02 & -0.02 & 0.01 \\
\hline \begin{tabular}{|l|} 
Parental warmth \\
(caregiver-reported)
\end{tabular} & & & $0.32 * * *$ & $0.46 * * *$ & & & $0.47^{* * *}$ & $* 0.51 * * *$ & & & $0.48^{* * *}$ & $* 0.51 * * *$ \\
\hline Behavior $\times$ Warmth & & & & $0.27^{* *}$ & & & & 0.10 & & & & $0.16^{*}$ \\
\hline $\mathrm{R}^{2}$ & 0.09 & 0.22 & 0.29 & 0.34 & 0.06 & 0.08 & 0.28 & 0.29 & 0.06 & 0.07 & 0.28 & 0.30 \\
\hline F for change in $R^{2}$ & $3.77^{*}$ & $8.50 * * *$ & $9.76 * * *$ & $9.72 * * *$ & 2.67 & $2.49 *$ & $8.95^{* * *}$ & $* 7.72 * * *$ & 2.67 & 2.00 & $8.83^{* * *}$ & * $8.21 * * *$ \\
\hline
\end{tabular}

Child sex, Child age, Adversity composite, Emotion coaching, Parental warmth, Validation, and Invalidation variables were centered at their means ${ }^{*} p<0.05 ;{ }^{* *} p<0.01 ; * * *<0.001$ 
The analysis examining parental warmth as a moderator of the association between emotion coaching and the adaptive functioning composite indicated that caregiver-reported emotion coaching $(b=0.23, p=0.02)$ and warmth $(b=32, p=0.001)$ both uniquely predicted adaptive functioning after accounting for exposure to adversity and the other covariates. The interaction of parental warmth and emotion coaching also was significant $(B=0.27, p=0.01)$, indicating that the association between emotion coaching and adaptive functioning depended on the level of parental warmth. The ROS results indicated that the region of significance for parental warmth was between 5.08 and 7.00 (a positive association); these values range from just below the mean to the maximum obtained value. Simple slopes for the association between emotion coaching and adaptive functioning then were explored at high and low levels of parental warmth (+/- 1 SD from the mean). Higher levels of emotion coaching significantly predicted adaptive functioning under high levels of parental warmth $(B=0.32, p=0.001)$, but not under low levels $(B=0.11, p=0.72)$. Figure 1 plots the simple slopes of the interaction.

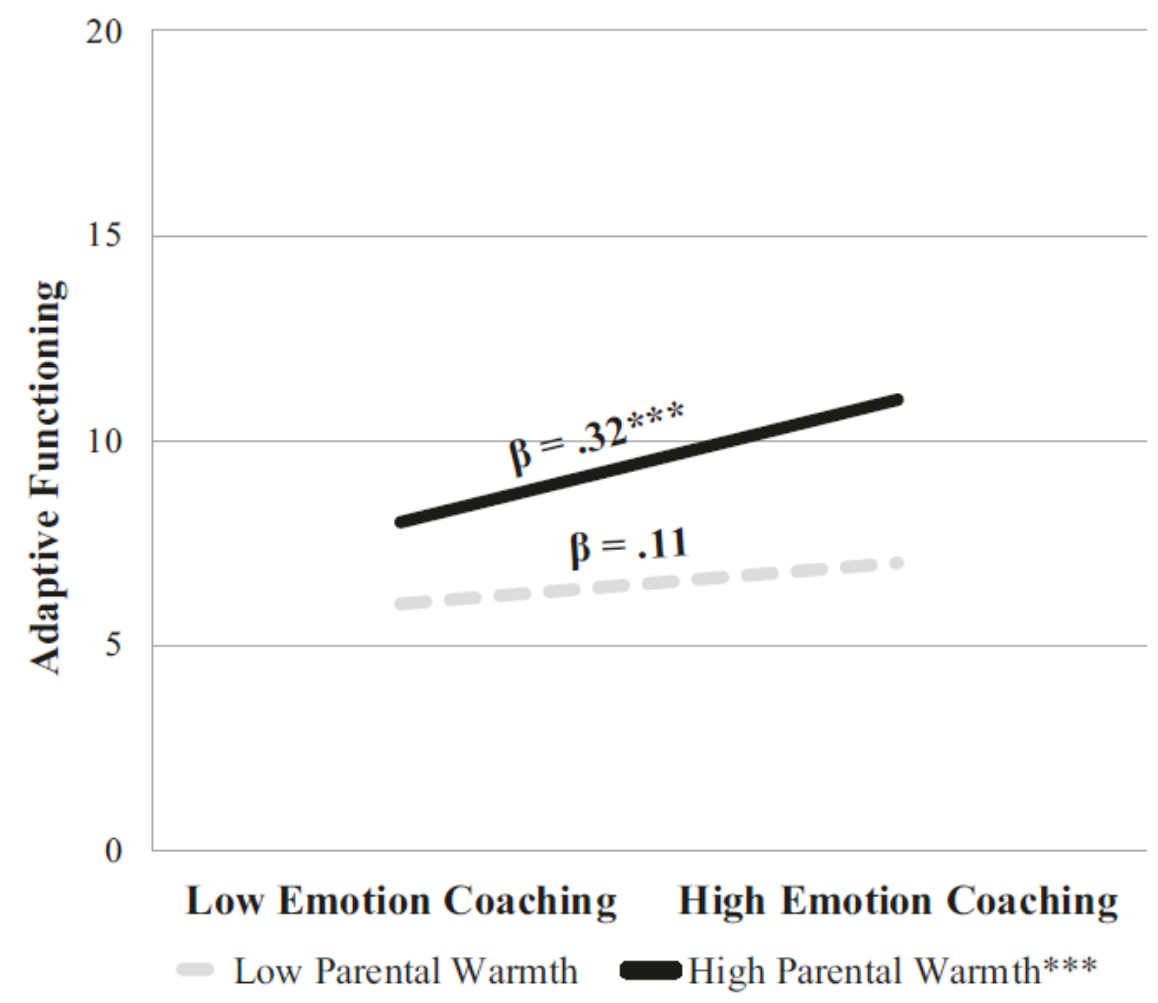

Fig. 1 Interaction of caregiver-reported parental warmth and emotion coaching behaviors in predicting adaptive functioning. ${ }^{* * *} \mathrm{p}<0.001$

The analysis examining observed parental invalidation and caregiver-reported warmth resulted in a significant unique association between adaptive functioning and warmth $(B=0.48, p=0.001)$, but not invalidating behaviors $(B=-0.02, p=0.97)$. The interaction between parental warmth and invalidating behaviors was significant $(\theta=0.16, p=0.04)$, indicating that the association between invalidating behaviors and adaptive functioning depended on the level of parental warmth. Results from the ROS indicate that the association between invalidation and adaptive functioning was significant (and negative) between the values of 1.00 and 1.22 , which reflects very low of parental warmth. Simple slope analyses showed that there was no association between invalidation and adaptive functioning 
$(B=0.01)$ at high levels of warmth $(+1 S D)$ and was negative $(B=-0.15)$ at low levels of warmth $(-1 S D)$; neither slope differed significantly from 0 (see Fig. 2).

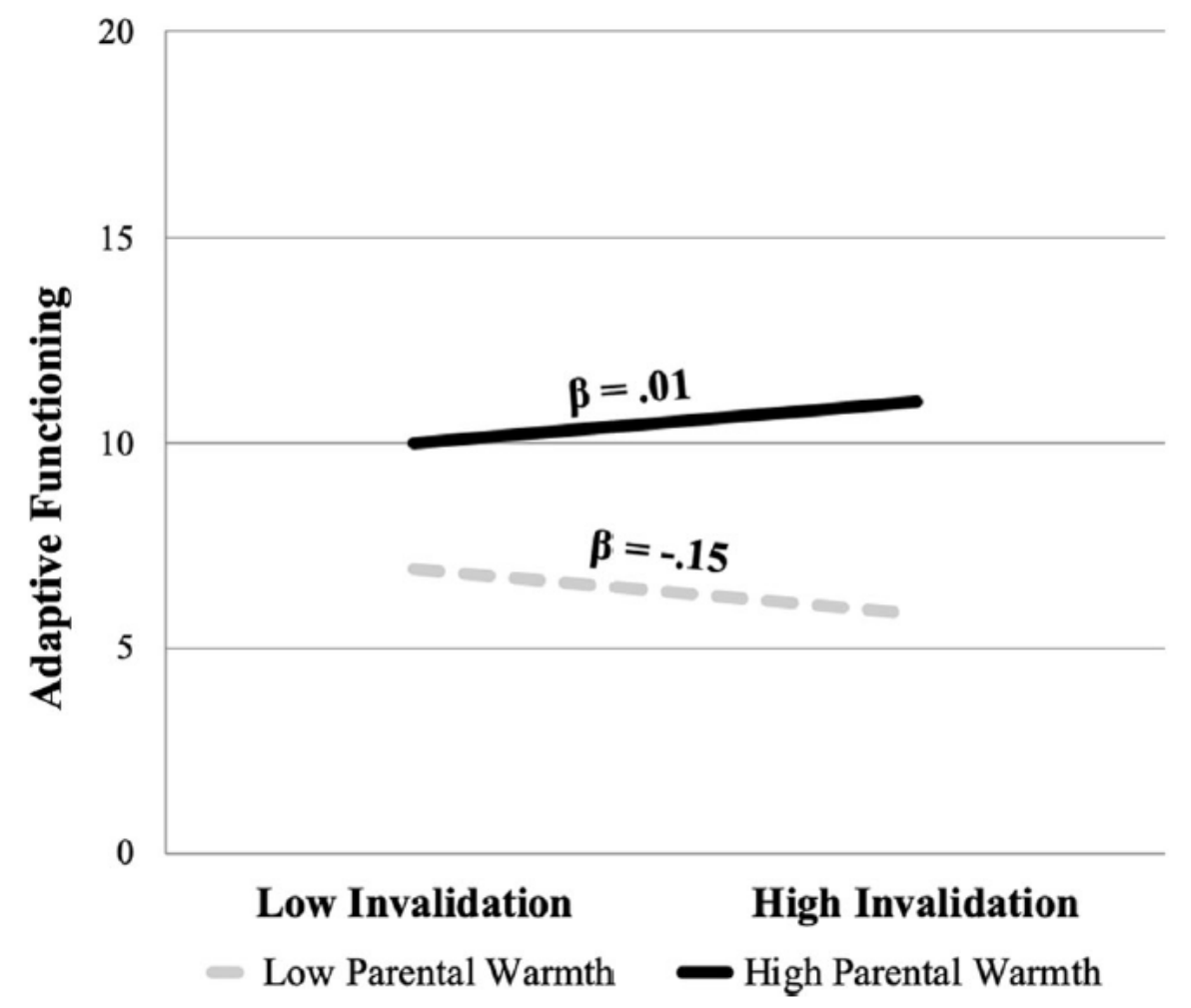

Fig. 2 Interaction of caregiver-reported parental warmth and observed invalidating behaviors in predicting adaptive functioning

\section{Discussion}

The present study investigated caregiving behaviors associated with adaptive functioning in preschoolers exposed to adversity. This is a critical developmental period because children who exhibit greater social competence and school readiness when they begin formal education demonstrate greater academic achievement, peer acceptance, and mental health in later years (Duncan et al. [21]; Henricsson and Rydell [33]). By using multiple indicators of healthy development, this study provides more comprehensive assessment of adaptive functioning than most previous research examining resilience in this age group. The findings show that, after accounting for children's exposure to adversity, sex, and age, both caregiver warmth and specific emotion socialization practices predicted better adjustment. Specifically, caregiver reports of emotion coaching and warmth uniquely predicted children's functioning, and warmth moderated the association between the adaptive functioning composite and both caregiver-reported emotion coaching and observed emotional invalidation. When caregivers reported that they attended to their children's emotions and provided guidance in managing them, children exhibited greater emotion regulation, social competence and school readiness; however, this association was significant only when caregivers were at or above the mean on the global measure of warmth. In contrast, engaging in invalidating behaviors when discussing their children's emotions predicted lower levels of adaptive functioning when caregivers were very low in warmth, but was not related to adaptive functioning for caregivers higher in warmth. 
These data demonstrate, first, that emotion coaching is uniquely related to young children's healthy development regardless of their level of exposure to adversity, and is distinct from caregivers' general level of warmth and supportiveness. As demonstrated in prior research, caregiver-reported warmth significantly predicted more adaptive functioning across domains, but self-reports of caregivers' efforts to help their children understand and manage their emotions added uniquely to the prediction of children's emotion regulation, social skills, school readiness, and behavioral adjustment. Observed parenting behavior was not correlated with children's adaptive functioning, which may reflect the larger pool of interactions caregivers have to draw on relative to the relatively brief interactions assessed in the study. Although method variance also may have contributed to the results, the inclusion of teachers as additional reporters of children's functioning and the unique associations for warmth and coaching suggest that monomethod variance cannot wholly explain the results.

The findings also support the idea that the quality of the caregiver-child relationship moderates the impact of particular parenting practices. Caregiver reports of emotion coaching were associated with more adaptive functioning only when it occurred in the context of a trusting and secure relationship. Attending to unpleasant emotions is difficult, but when a caregiver who generally is warm and nurturing helps their child explore their emotional experiences, it is likely to promote the child's capacity to recognize, understand, and express painful feelings. In contrast, the same kind of exploration may feel intrusive or could elicit shame if conducted by a caregiver who tends to be critical or unsupportive. Similarly, the interaction between caregiver-reported warmth and observed invalidation suggests that dismissing, ignoring, and criticizing children's emotional experiences has a particularly pernicious effect when it occurs in the context of a cold or distant caregiver-child relationship. The fact that these interactions included caregiver variables assessed via self-report (emotion coaching) and observation (invalidation) and using caregiver and teacher reports of children's functioning provides greater confidence in their validity.

Recent studies have provided evidence that emotion socialization is related to adjustment in children who have experienced significant adversity (Ellis et al. [24]; Katz and Windecker-Nelson [40]), but this is the first investigation to show that emotion coaching has both unique and interactive associations with a multifaceted measure of adaptive functioning in economically disadvantaged preschoolers. The preschoolers in this study had been exposed to substantial levels of adversity in addition to poverty: Caregivers reported that $90 \%$ of the children had experienced at least one significant adverse experience during their lifetime, with nearly $2 / 3$ exposed to up to 5 adverse events, including interparental aggression, community violence, peer victimization, and incarceration of a family member. Despite experiencing high levels of adversity, a majority of the preschoolers demonstrated healthy functioning in at least one of the domains assessed (i.e., emotion regulation, school readiness, social skills, and behavioral adjustment); however, only $23 \%$ exhibited above-average functioning in three or more of these domains.

Identifying factors associated with adaptive functioning in high-risk preschoolers has significant implications for prevention. Behaviors such as labeling and reflecting children's emotions, asking openended questions that invite children to explore and understand their feelings, and using a supportive tone and body language can be learned and enhanced in caregivers who do not regularly use these skills with their children. There are a number of prevention and intervention programs targeted 
specifically for preschool aged children exposed to adversity, including therapeutic interventions in clinical (e.g. Incredible Years Parenting Program, Borden et al. [ 7]; Parent Child Interaction TherapyEmotional Development, Luby et al. [48]; Tuning in to Kids, Wilson et al. [74]), and school settings (e.g. Head Start REDI Program, Nix et al. [59]). Although these programs have extensive empirical support of their effectiveness, evaluation studies have not specifically examined whether emotion socialization is related to children's functioning; the current results suggest that these programs could be more effective in promoting adaptive functioning if they placed more emphasis on teaching caregivers specific emotion coaching behaviors while also encouraging warmth and support.

\section{Limitations and Future Directions}

Although the present findings offer insight into the role of emotion socialization in at-risk preschoolers, this research is not without its limitations. First, the data are cross-sectional and cannot be used to infer causal relationships between caregiver behaviors and adaptive functioning. Caregivers' behavior during the conversation task is likely to be influenced by children's ability to express their emotions, and longitudinal research is needed to assess potential bidirectional effects between caregiver emotion socialization behaviors and child adjustment. Second, the observational task was relatively brief and provides a limited sample of how caregivers respond to their children's emotions, which may have attenuated any associations of resilience with validation and invalidation. Third, the study assessed only one caregiver. It is plausible that having more than one caregiver who consistently validates and coaches children's emotions will have a more powerful effect, but is unclear how having caregivers with different interaction styles may impact children's developmental outcomes. Relatedly, children spend a significant amount of their day with their teachers, who likely employ a number of different emotion socialization strategies to help children develop greater developmental competence. Finally, most of the caregivers were female and African-American, and so the results are not necessarily generalizable to other demographic groups.

In addition to investigating the association between emotion coaching and children's resilience over time and with multiple caregivers, further research is needed to understand whether cultural differences exist in how caregivers engage in emotional validation and invalidation practices. Prior studies of emotion socialization primarily have utilized middle-class, Caucasian samples (Eisenberg et al. [23]; Zeman et al. [77]), and although the coding schemes utilized to assess parental validation and invalidation in this study have been used with high-risk families (Shipman et al. [71]), the demographic characteristics of the samples used to validate the coding schemes were not reported (Schneider and Shipman [67]). Therefore, it is unclear if they adequately assess parenting behaviors demonstrated by caregivers from diverse ethnic and socioeconomic backgrounds. Adaptive parenting strategies have been shown to differ across cultures (Deater-Deckard et al. [16]; Denham et al. [18]), and a recent review reported that some studies have found differences in how African American and European American caregivers respond to their children's emotions (Labella [43]). For example, there is evidence that African American parents exhibit less supportive responses to their children's unpleasant emotions than do European American parents (Dunbar et al. [20]), but that nonsupportive responses predict more adaptive outcomes, such as lower levels of aggression, in African American families (Labella [43]). These preliminary findings highlight the need for culturally-sensitive research that 
examines whether there may be different ways to foster children's adaptive functioning in diverse populations.

These findings provide insight into how caregiver warmth and supportiveness may impact the relationship between emotion socialization behaviors and preschooler's adaptive functioning. Emotion socialization, however, is just one type of parenting behavior found to predict children's well-being; other parenting practices, including monitoring, discipline effectiveness, problem-solving, also are related to more adaptive outcomes in youths exposed to adversity (Howell et al. [36]). For example, actively providing structure and guidance to children on appropriate behavior during daily routines has been shown to predict better academic functioning in children exposed to intimate partner violence (David et al. [15]). To develop a more comprehensive understanding of the relation between caregiving behaviors and child resilience, further research is needed that examines emotion socialization in relation to other parenting practices, and the unique and combined effects of these practices on children's functioning (Criss et al. [12]; Graham-Bermann et al. [29]).

In summary, the current study offers a unique contribution to resilience research by using a multimethod, multi-informant design to examine specific caregiver behaviors associated with healthy development in preschoolers exposed to adversity. The results suggest that caregivers who do more emotion coaching and avoid invalidating or dismissing their children's emotional experiences in the context of a generally warm and supportive relationship can help preschoolers develop greater emotion regulation, social skills, and school readiness. The capacity to recognize and regulate emotions is important in a variety of domains, including peer and academic settings (Brophy-Herb et al. [ 8]), and prevention programs and parenting interventions may be more effective if they incorporate specific practices related to children's capacity to manage their emotions and behaviors.

\section{Acknowledgements}

We thank our undergraduate research assistants for their assistance conducting this study, as well as the Head Start families that participated.

\section{Author Contributions}

K.Y. designed and executed the study, analyzed the data, wrote the paper. C.M. collaborated with the design and writing of the study. J.G. collaborated in the study design and writing and editing of the final manuscript.

\section{Compliance with Ethical Standards}

\section{Conflict of Interest}

The authors declare that they have no conflict of interest.

\section{Ethical Approval}

All procedures involving human participants were in accordance with the ethical standards of the institutional research committee of Marquette University and with the 1964 Helsinki declaration and its later amendments or comparable ethical standards. 


\section{Informed Consent}

Informed parental consent and informed child assent was obtained from all participants in this study.

Publisher's note Springer Nature remains neutral with regard to jurisdictional claims in published maps and institutional affiliations.

\section{References}

Achenbach TM, Rescorla L. ASEBA School-Age Forms and Profiles. 2001: Burlington, VT; Research Center for Children, Youth, and Families

Aiken LS, West SG. Multiple regression: Testing and interpreting interactions. 1991: Thousand Oaks, CA; Sage

Appleyard K, Egeland B, Dulmen MH, Alan Sroufe L. When more is not better: the role of cumulative risk in child behavior outcomes. Journal of Child Psychology and Psychiatry. 2005; 46: 235-245. 10.1111/j.1469-7610.2004.00351.x

Banyard VL, Williams LM. Women's voices on recovery: a multi-method study of the complexity of recovery from child sexual abuse. Child Abuse \& Neglect. 2007; 31: 275-290. 10.1016/j.chiabu.2006.02.016

Bell T, Romano E, Flynn RJ. Profiles and predictors of behavioral resilience among children in child welfare. Child Abuse \& Neglect. 2015; 48: 92-103. 10.1016/j.chiabu.2015.04.018

Blair C. School readiness: integrating cognition and emotion in a neurobiological conceptualization of children's functioning at school entry. American Psychologist. 2002; 57: 111-127. 10.1037//0003-066X.57.2.111

Borden LA, Schultz TR, Herman KC, Brooks CM. The Incredible Years Parent Training Program: Promoting resilience through evidence-based prevention groups. Group Dynamics: Theory, Research, and Practice. 2010; 14: 230-241. 10.1037/a0020322

Brophy-Herb HE, Stansbury K, Bocknek E, Horodynski MA. Modeling maternal emotion-related socialization behaviors in a low-income sample: relations with toddlers' self-regulation. Early Childhood Research Quarterly. 2012; 27: 352-364. 10.1016/j.ecresq.2011.11.005

Buhs ES, Ladd GW, Herald SL. Peer exclusion and victimization: processes that mediate the relation between peer group rejection and children's classroom engagement and achievement?. Journal of Educational Psychology. 2006; 98: 1-13. 10.1037/0022-0663.98.1.1

Centers for Disease Control and Prevention (2016). Developmental Milestones. Centers for Disease Control and Prevention. www.cdc.gov/ncbddd/actearly/milestones/index.html.

Cicchetti D, Rogosch FA. Personality, adrenal steroid hormones, and resilience in maltreated children: a multilevel perspective. Development and Psychopathology. 2007; 19: 787-809. $10.1017 /$ S09545794070003993409470

Criss MM, Lee TK, Morris AS, Cui L, Bosler CD, Shreffler KM, Silk JS. Link between monitoring behavior and adolescent adjustment: an analysis of direct and indirect effects. Journal of Child and Family Studies. 2015; 24: 668-678. 10.1007/s10826-013-9877-0

Cunningham JN, Kliewer W, Garner PW. Emotion socialization, child emotion understanding and regulation, and adjustment in urban African American families: differential associations across child gender. Development and Psychopathology. 2009; 21: 261-283. 10.1017/S0954579409000157

Data Resource Center on Child and Adolescent Health (2017). National Survey of Children's Health, 2016. [Custom cross-tabulation]. childhealthdata.org/browse/survey/results? $q=4783 \& r=1$. 
David KB, LeBlanc MM, Self-Brown S. Violence exposure in young children: child-oriented routines as a protective factor for school readiness. Journal of Family Violence. 2015; 30: 303-314. 10.1007/s10896-015-9676-z

Deater-Deckard K, Dodge KA, Bates JE, Pettit GS. Physical discipline among African American and European American mothers: links to children's externalizing behaviors. Developmental Psychology. 1996; 32: 1065-1072. 10.1037/0012-1649.32.6.1065

Denham SA, Blair KA, DeMulder E, Levitas J, Sawyer K, Auerbach-Major S, Queenan P. Preschool emotional competence: pathway to social competence?. Child Development. 2003; 74: 238-256. 10.1111/1467-8624.00533

Denham, S. A., Caal, S., Bassett, H. H., Benga, O., \& Geangu, E. (2005). Listening to parents: cultural variations in the meaning of emotions and emotion socialization. Cognition, Brain, Behavior, 8 , 321-349. http://denhamlab.gmu.edu/Publications.

Denham SA, Mitchell-Copeland J, Strandberg K, Auerbach S, Blair K. Parental contributions to preschoolers' emotional competence: direct and indirect effects. Motivation and Emotion. 1997; 21: 65-86. 10.1023/A:1024426431247

Dunbar AS, Leerkes EM, Coard SI, Supple AJ, Calkins S. An integrative conceptual model of parental racial/ethnic and emotion socialization and links to children's social-emotional development among African American families. Child Development Perspectives. 2017; 11: 16-22. 10.1111/cdep.12218

Duncan GJ, Dowsett CJ, Claessens A, Magnuson K, Huston AC, Klebanov P, Japel C. School readiness and later achievement. Developmental Psychology. 2007; 43: 1428-1446. 10.1037/00121649.43.6.1428

Eisenberg N, Cumberland A, Spinrad TL. Parental socialization of emotion. Psychological Inquiry. 1998; 9: 241-273. 10.1207/s15327965pli0904_11513625

Eisenberg N, Zhou Q, Spinrad TL, Valiente C, Fabes RA, Liew J. Relations among positive parenting, children's effortful control, and externalizing problems: a three-wave longitudinal study. Child Development. 2005; 76: 1055-1071. 10.1111/j.1467-8624.2005.00897.x1351058

Ellis $\mathrm{BH}$, Alisic E, Reiss A, Dishion T, Fisher PA. Emotion regulation among preschoolers on a continuum of risk: the role of maternal emotion coaching. Journal of Child and Family Studies. 2014; 23: 965-974. 10.1007/s10826-013-9752-z

Epstein M, Synhorst L. Preschool Behavioral and Emotional Rating Scale (PreBERS): test-retest reliability and inter-rater reliability. Journal of Child and Family Studies. 2008; 17: 853-862. 10.1007/s10826-008-9194-1

Fay-Stammbach T, Hawes DJ, Meredith P. Child maltreatment and emotion socialization: associations with executive function in the preschool years. Child Abuse \& Neglect. 2017; 64: 1-12. 10.1016/j.chiabu.2016.12.004

Finkelhor D, Hamby SL, Ormrod R, Turner H. The Juvenile Victimization Questionnaire: Reliability, validity, and national norms. Child Abuse \& Neglect. 2005; 29: 383-412. 10.1016/j.chiabu.2004.11.001

Gottman JM, Katz LF, Hooven C. Meta-emotion: How families communicate emotionally. 1997: Mahwah, NJ; Lawrence Erlbaum Associates, Publishers

Graham-Bermann SA, Gruber G, Howell KH, Girz L. Factors discriminating among profiles of resilience and psychopathology in children exposed to intimate partner violence (IPV). Child Abuse \& Neglect. 2009; 33: 648-660. 10.1016/j.chiabu.2009.01.002

Gross JJ, Muñoz RF. Emotion regulation and mental health. Clinical Psychology: Science and Practice. 1995; 2 : 151-164. 10.1111/j.1468-2850.1995.tb00036.x 
Paterson AD, Babb KA, Camodeca A, Goodwin J, Hakim-Larson J, Voelker S, Gragg M. Emotion-Related Parenting Styles (ERPS): a short form for measuring parental meta-emotion philosophy. Early Education and Development. 2012; 23: 583-602. 10.1080/10409289.2011.569316

Hayes AF, Matthes J. Computational procedures for probing interactions in OLS and logistic regression: SPSS and SAS implementations. Behavior Research Methods. 2009; 41: 924-936. 10.3758/BRM.41.3.924

Henricsson L, Rydell A. Children with behaviour problems: the influence of social competence and social relations on problem stability, school achievement and peer acceptance across the first six years of school. Infant \& Child Development. 2006; 15: 347-366. 10.1002/icd.448

Herrenkohl TI, Herrenkohl RC. Examining the overlap and prediction of multiple forms of child maltreatment, stressors, and socioeconomic status: a longitudinal analysis of youth outcomes. Journal of Family Violence. 2007; 22: 553-562. 10.1007/s10896-007-9107-x

Howell DC. Statistical methods for psychology. 20076th ed.: Belmont, CA; Thomson Wadsworth

Howell KH, Graham-Bermann SA, Czyz E, Lilly M. Assessing resilience in preschool children exposed to intimate partner violence. Violence and Victims. 2010; 25: 150-164. 10.1891/0886-

6708.25.2.150

Katz LF, Hessler DM, Annest A. Domestic violence, emotional competence, and child adjustment. Social Development. 2007; 16: 513-538. 10.1111/j.1467-9507.2007.00401.x

Katz LF, Hunter E, Klowden A. Intimate partner violence and children's reaction to peer provocation: the moderating role of emotion coaching. Journal of Family Psychology. 2008; 22: 614-621. $10.1037 / \mathrm{a} 00127932950618$

Katz LF, Stettler N, Gurtovenko K. Traumatic stress symptoms in children exposed to intimate partner violence: the role of parent emotion socialization and children's emotion regulation abilities. Social Development. 2016; 25: 47-65. 10.1111/sode.12151

Katz LF, Windecker-Nelson B. Domestic violence, emotion coaching, and child adjustment. Journal of Family Psychology. 2006; 20: 56-67. 10.1037/0893-3200.20.1.56

Kim J, Cicchetti D. Longitudinal pathways linking child maltreatment, emotion regulation, peer relations, and psychopathology. Journal of Child Psychology and Psychiatry. 2010; 51: 706-716. 10.1111/j.1469-7610.2009.02202.x20050965

Klika JB, Herrenkohl TI. A review of developmental research on resilience in maltreated children. Trauma, Violence, \& Abuse. 2013; 14: 222-234. 10.1177/1524838013487808

Labella MH. The sociocultural context of emotion socialization in African American families. Clinical Psychology Review. 2018; 59: 1-15. 10.1016/j.cpr.2017.10.006

Ladd GW. Children's peer relations and social competence: A century of progress. 2005: Chicago, IL; Yale University Press

Lemerise EA. Social development quartet: emotion socialization in the context of psychopathology and risk. Social Development. 2016; 25: 3-7. 10.1111/sode.12167

Lieberman AF, Van Horn P, Ippen CG. Toward evidence-based treatment: child-parent psychotherapy with preschoolers exposed to marital violence. Journal of the American Academy of Child \& Adolescent Psychiatry. 2005; 44: 1241-1248. 10.1097/01.chi.0000181047.59702.58

Lonigan CJ, Burgess SR, Anthony JL. Development of emergent literacy and early reading skills in preschool children: evidence from a latent-variable longitudinal study. Developmental Psychology. 2000; 36: 596-613. 10.1037/0012-1649.36.5.596

Luby J, Lenze S, Tillman R. A novel early intervention for preschool depression: findings from a pilot randomized controlled trial. Journal of Child Psychology and Psychiatry. 2012; 53: 313-322. 10.1111/j.1469-7610.2011.02483.x 
Lunkenheimer ES, Shields AM, Cortina KS. Parental emotion coaching and dismissing in family interaction. Social Development. 2007; 16: 232-248. 10.1111/j.1467-9507.2007.00382.x

Luthar SS Cohen DJ, Cicchetti D. Resilience in development: A synthesis of research across five decades. Development and psychopathology, Vol. 3: Risk, disorder and adaptation. 2006: Hoboken, NJ; Wiley \& Sons: 739-957

Luthar SS, Cicchetti D, Becker B. The construct of resilience: a critical evaluation and guidelines for future work. Child Development. 2000; 71: 543-562. 10.1111/1467-8624.001641885202

Luthar, S. S., \& Cushing, G. (1999) Measurement issues in the empirical study of resilience. In M. D. Glantz, J. L. Johnson (Eds.), Measurement issues in the empirical study of resilience. Resilience and development: Positive life adaptations. (pp. 129-160). New York, NY: Kluwer Academic Publishers.

Masten AS. Ordinary magic: Resilience in development. 2014: New York, NY; Guilford Publications, Inc Masten AS, Best KM, Garmezy N. Resilience and development: contributions from the study of children who overcome adversity. Development and Psychopathology. 1990; 2: 425-444. $10.1017 / \mathrm{S} 0954579400005812$

Masten AS, Burt KB, Coatsworth JD Cohen DJ, Cicchetti D. Competence and psychopathology in development. Development and psychopathology, Vol. 3: Risk, disorder and adaptation. 2006: Hoboken, NJ; Wiley \& Sons: 696-738

Masten AS, Coatsworth JD. The development of competence in favorable and unfavorable environments: lessons from research on successful children. American Psychologist. 1998; 53: 205-220. 10.1037/0003-066X.53.2.205

Masten AS, Tellegen A. Resilience in developmental psychopathology: contributions of the project competence longitudinal study. Development and Psychopathology. 2012; 24: 345-361. 10.1017/S095457941200003X

McCabe PC, Altamura M. Empirically valid strategies to improve social and emotional competence of preschool children. Psychology in the Schools. 2011; 48: 513-540. 10.1002/pits.20570

Nix RL, Bierman KL, Domitrovich CE, Gill S. Promoting children's social-emotional skills in preschool can enhance academic and behavioral functioning in kindergarten: Findings from Head Start REDI. Early Education \& Development. 2013; 24: 1000-1019. 10.1080/10409289.2013.825565

Nordness, P. D., Epstein, M. H., \& Synhorst, L. (2009). Convergent validity and test-retest reliability of the Preschool Behavioral and Emotional Behavior Rating Scale: Parents as respondents. Early Childhood Services, 3, 51-60. https://digitalcommons.unomaha.edu/spedfacpub/1/.

Obradović J, Burt KB, Masten AS. Testing a dual cascade model linking competence and symptoms over 20 years from childhood to adulthood. Journal of Clinical Child \& Adolescent Psychology. 2009; 39: 90-102. 10.1080/15374410903401120

Pearl E. Childhood Trust Events Survey: Child and Caregiver Versions. 20002nd ed.: Cincinnati, OH; Trauma Treatment Training Center

Posner MI, Rothbart MK. Developing mechanisms of self-regulation. Development and Psychopathology. 2000; 12: 427-441. 10.1017/S0954579400003096

Quiroga A, López-Rodríguez L, Willis GB. Parental support buffering the effect of violence on adolescents' depression: gender differences. Journal of Interpersonal Violence. 2017; 32: 10681086. 10.1177/0886260515587664

Rohner RP, Saavedra JM, Granum EO Rohner RP, Khaleque A. Parental acceptance-rejection questionnaire: Test manual. Handbook for the study of parental acceptance and rejection. 1991: Storrs, CT; University of Connecticut, Rohner Research: 17-48 
Rutter M. Implications of resilience concepts for scientific understanding. Annals of the New York Academy of Sciences. 2006; 1094: 1-12. 10.1196/annals.1376.002

Schneider, R. A., \& Shipman, K. L. (2005). Maternal emotion socialization and risk for child depression. Unpublished manuscript.

Shaffer A, Suveg C, Thomassin K, Bradbury LL. Emotion socialization in the context of family risks: Links to child emotion regulation. Journal of Child and Family Studies. 2012; 21: 917-924. 10.1007/s10826-011-9551-3

Shields A, Cicchetti D. Emotion regulation among school-age children: the development and validation of a new criterion Q-sort scale. Developmental Psychology. 1997; 33: 906-916. 10.1037/00121649.33.6.906

Shipman, K., Fitzgerald, M. M., \& Torres, M. M. (2015). Parent-Child Interaction Task and Global Coding Scales. [Code book]. Institute of Behavioral Science, University of Colorado.

Shipman KL, Schneider R, Fitzgerald MM, Sims C, Swisher L, Edwards A. Maternal emotion socialization in maltreating and non-maltreating families: Implications for children's emotion regulation. Social Development. 2007; 16: 268-285. 10.1111/j.1467-9507.2007.00384.x

Straus MA, Douglas EM. A short form of the revised conflict tactics scales, and typologies for severity and mutuality. Violence and Victims. 2004; 19: 507-520. 10.1891/vivi.19.5.507.63686

Thompson RA. Stress and child development. The Future of Children. 2014; 24: 41-59. $10.1353 /$ foc. 2014.0004

Wilson KR, Havighurst SS, Harley AE. Tuning in to Kids: an effectiveness trial of a parenting program targeting emotion socialization of preschoolers. Journal of Family Psychology. 2012; 26: 56-65. $10.1037 / \mathrm{a} 0026480$

Yule K, Houston J, Grych J. Resilience in children exposed to violence: a meta-analysis of protective factors across ecological contexts. Clinical Child and Family Psychology Review. 2019; 22: 406431. 10.1007/s10567-019-00293-1

Zeman J, Dallaire D, Borowski S. Socialization in the context of risk and psychopathology: maternal emotion socialization in children of incarcerated mothers. Social Development. 2016; 25: 66-81. 10.1111/sode.12117

Zeman J, Shipman K, Suveg C. Anger and sadness regulation: predictions to internalizing and externalizing symptoms in children. Journal of Clinical Child \& Adolescent Psychology. 2002; 31: 393-398. 10.1207/S15374424JCCP3103_11 